M. J. Weidmann

M. Gold

O. Dörzapf

\section{Postzosterische granulomatöse Dermatitis mit Nachweis von Varizella-Zoster-Virus-DNA}

\section{Granulomatous Dermatits Following Herpes Zoster with Detection of Varicella} Zoster Virus DNA - Case Report

\section{Zusammenfassung}

Das Auftreten einer granulomatösen Dermatitis nach einem Herpes Zoster ist ungewöhnlich und eher selten. Auch die Pathogenese bleibt weiterhin unklar. Wir berichten von einer 55-jährigen Patientin, die im Anschluss an einen ausgedehnten Herpes zoster rotbraune Papeln im gleichen Ausbreitungsgebiet entwickelte. Die Patientin litt seit ungefähr $1 \frac{1}{2}$ Jahren an einer Hepatitis C-Virus-Infektion. Durch die Histologie konnte der initiale klinische Diagnoseverdacht eines Lichen ruber ausgeschlossen und eine lichenoide granulomatöse Dermatitis bestätigt werden. Mittels Polymerase-Ketten-Reaktion, die aus einem genommenen Abstrich durchgeführt wurde, gelang, drei Monate nach Auftreten des Herpes Zoster, der Nachweis von Varizella-Zoster-Virus-DNA. Der Therapieversuch mit einer oralen antiviralen Therapie führte nicht zum Abheilen der Hauteffloreszenzen. Mit der topischen Anwendung eines Kortikosteroids konnte eine deutliche Befundbesserung erreicht werden.

\section{Abstract}

The occurrence of a granulomatous dermatitis following herpes zoster is uncommon and rather rare. Also pathogenesis still remains unclear. We report on a 55 year old female patient, who developed red brown papules following an extensive herpes zoster in the same area. The patient was suffering from a chronic hepatitis $C$ since nearly one and a half years. Histopathologically a lichenoide granulomatous dermatitis was found, and the first clinical diagnosis of a lichen ruber could be excluded. By means of polymerase chain reaction, made from a taken swab, varizella zoster virus DNA was identified, three months after the occurrence of herpes zoster. Neither a therapy trail with topical corticosteroids nor an oral antiviral therapy could make the skin lesions disappear completely.

\section{Einleitung}

Das Auftreten einer neuen Hauterkrankung nach Abheilung einer Dermatose an gleicher Stelle wird als isotope Reaktion bezeichnet [1]. Nach einem Herpes Zoster wurde dies bereits mehrfach beschrieben. Im gleichen Ausbreitungsgebiet wurden akneiforme Veränderungen, Lichen ruber planus, eine Furunkulose, Psoriasis vulgaris, Morphea oder eine eosinophile Dermatitis beob- achtet. Granulomatöse Erkrankungen wie Granuloma anulare, Granuloma anulare perforans, tuberkuloide Granulome, sarkoidale Granulome, granulomatöse Vaskulitis oder eine unklassifizierbare granulomatöse Dermatitis scheinen jedoch häufiger aufzutreten. Auch maligne Erkrankungen, wie zum Beispiel das Kaposi-Sarkom, Lymphome oder Basalzell- und Plattenepithelkarzinome, wurden beschrieben $[3,4,13]$. Das zeitliche Auftreten der Hautveränderungen nach einem Herpes zoster ist hierbei 
sehr variabel und erstreckt sich zwischen einem unmittelbaren Erscheinen bis zu einer Latenzzeit von bis zu vier Jahren $[3,14]$. Der Nachweis von Varizella-Zoster-DNA in granulomatösen Hautveränderungen gelang bisher nur in wenigen Fällen $[3,4,14]$. Bemerkenswert ist im nachfolgenden Fall sicherlich auch der Zusammenhang mit der seit ungefähr $1^{1} / 2$ Jahren bestehenden Hepatitis C-Virus-Infektion. Unbestritten ist diese ein Trigger für das Auftreten verschiedenster Hauterkrankungen und extrahepatischer Manifestationen [6,12]. Verschiedenste immunologische Phänomene spielen hierbei eine Rolle [12]. Magro $\mathrm{CM}$ et al. hielten bereits einen Zusammenhang zwischen dem Auftreten einer lichenoiden, granulomatösen Hauterscheinung und einer hepatobiliären Erkrankung für möglich [9].

\section{Fallbericht}

\section{Anamnese und Hautbefund}

Bei einer 55-jährigen Patientin mit einer seit ungefähr $1 \frac{1}{1} / 2$ Jahren bekannter Hepatitis C-Virus-Infektion kam es im Mai 2004 zum Ausbruch eines ausgeprägten Herpes Zoster. Der großflächige Befund erstreckte sich von der linken Lumbal- und Glutealregion bis auf den linken medialen Oberschenkel (Abb. 1 und 2). Die Patientin wurde daraufhin stationär ins nahe gelegene Bezirkskrankenhaus eingewiesen. Dort wurde sie mit Aciclovir intravenös (5 mg/ $\mathrm{kg} / \mathrm{KG}$ ) über 14 Tage behandelt. Daraufhin kam es zur Rückbildung der Hauteffloreszenzen. Zurück blieb lediglich eine Hyperpigmentierung an den ehemals befallenen Hautarealen. Im Juli/ August 2004 kam es jedoch zum Auftreten von rotbraunen, zum Teil auch konfluierenden Papeln mit isotopem Verteilungsmuster, die mit einem Lichen ruber vergleichbar und zudem in lichenoider Anordung waren (Abb. 1 und 2). Zunächst wurde die Patientin mit Beta Cordes-Creme in Eucerin cum aqua zu gleichen Teilen behandelt. Unter dieser Therapie kam es aber nicht zur vollständigen Abheilung der befallenen Hautareale. Auf Grund dessen wurde bei Wiedervorstellung, Anfang September 2004, schließlich eine Probeentnahme und eine PCR-Untersuchung aus einem Abstrich zur Diagnosesicherung veranlasst.

\section{Histologische Untersuchung (Abb. 3 u. 4)}

In der zur Diagnosesicherung entnommenen Probebiopsie an der LWS zeigte die Epidermis eine deutliche basale Hyperpigmentierung sowie eine minimale fleckförmige basale Spongiose. An einer Stelle zeigte sich ein flacher Parakeratosehügel unter einer korbgeflechtartigen orthokeratotischen Hornschicht. Im mittleren und oberen Corium fanden sich sehr dichte, betont perivaskuläre Rundzellinfiltrate sowie kleinfleckige interstitielle granulomatöse Infiltrate.Der Befund war gut vereinbar mit einer postzosterischen granulomatösen Dermatitis.

Molekulargenetische Untersuchung des lumbalen Abstrichs (Privatdozent Dr. Bezold, Neu-Ulm)

Aus dem lumbalen Abstrich wurde eine PCR-Untersuchung auf Varizella-Zoster-Virus veranlasst [7]. Das Ergebnis sprach für eine Infektion mit Varizella-Zoster-Virus. Zu beachten ist hierbei immer, dass nur spezifische DNA nachgewiesen wurde, so dass nicht zwischen aktiven und abgetöteten Mikroorganismen unterschieden werden kann. Ebenso ist es möglich, dass die klinische

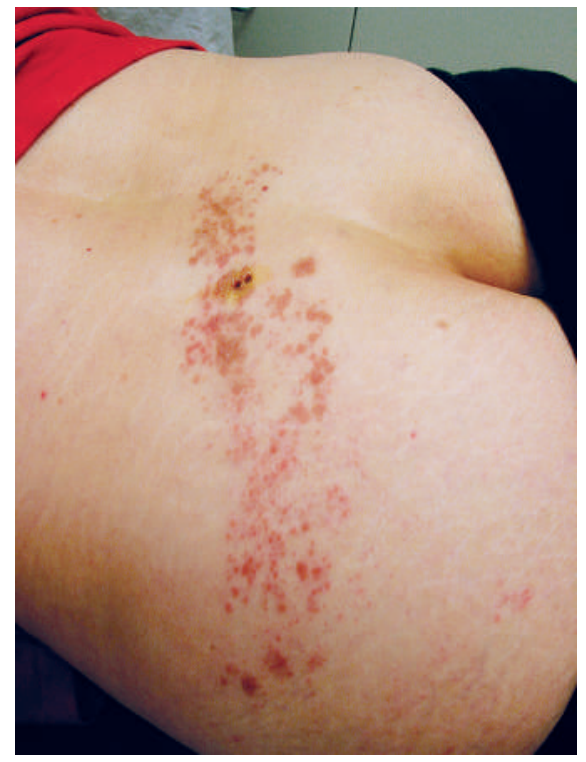

Abb. 1 Postzosterische granulomatöse Dermatitis in der Glutealregion.

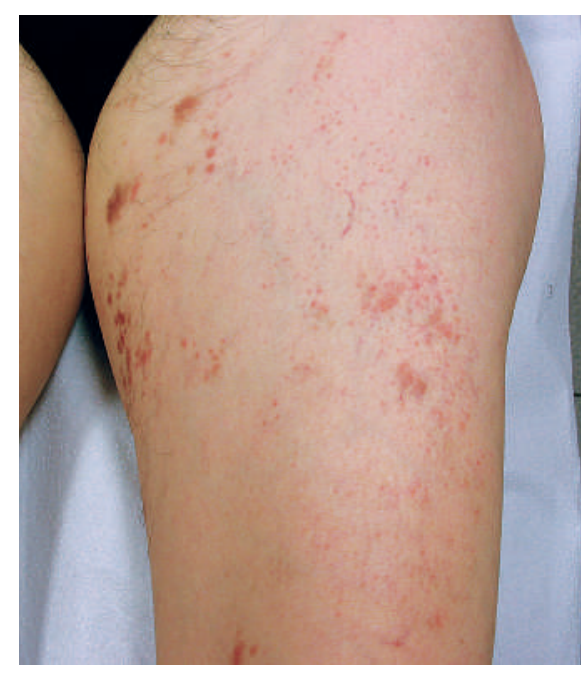

Abb. 2 Postzosterische granulomatöse Dermatitis im Bereich des linken Oberschenkels.

Symptomatik nicht durch den Erreger per se, sondern durch die von ihm hervorgerufene Entzündungsreaktion verursacht wird.

\section{Therapie und Verlauf}

Da sich der initiale Diagnoseverdacht eines Lichen ruber histologisch nicht bestätigen ließ und die PCR-Untersuchung auf Varizella-Zoster-Virus positiv ausfiel, wurde eine orale, antivirale Therapie mit Brivudin-Tabletten, zunächst für 7 Tage, eingeleitet. Diese Therapieoption wurde eingeschlagen, da in ähnlichen Fällen bereits gute Heilungsergebnisse berichtet wurden. Dies geschah nach Absprache mit der Hausärztin der Patientin, die sich auch zur regelmäßigen Überprüfung der Leberwerte bereit erklärte. Unter dieser Therapie kam es zu einer deutlichen Besserung der Hauteffloreszensen. Da die Patientin aber weiterhin über starken Juckreiz berichtete, wurde ihr angeraten, ihre Hepatitis-Therapie in Absprache mit ihrer Hausärztin, die ihr bisher nur ein pflanzliches Präparat verordnet hatte, zu intensivieren. Gleichzeitig wurde eine stärkere topische Kortikosteroidtherapie verordnet. 


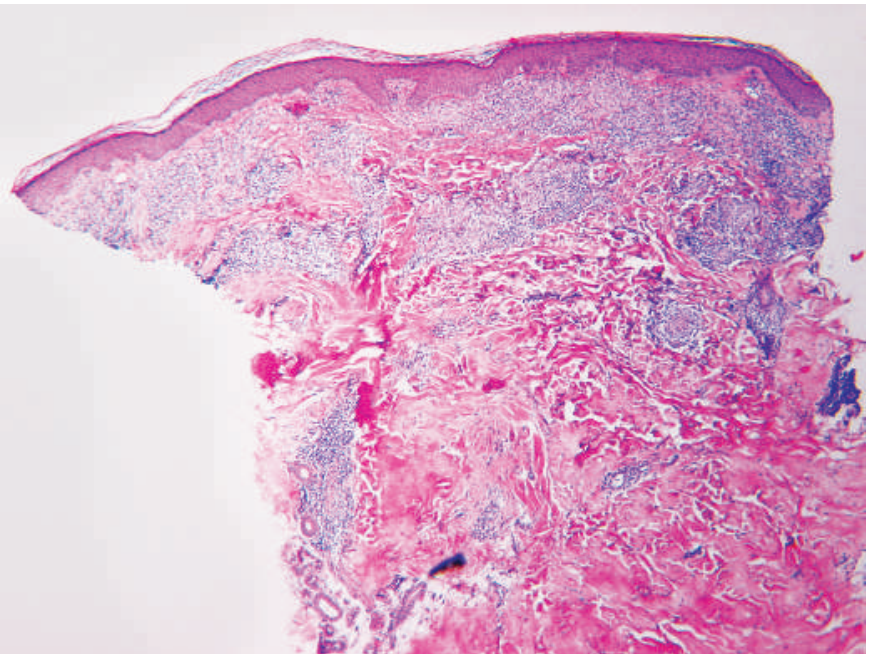

Abb. 3 Granulomatöse Dermatitis - Übersichtsaufnahme

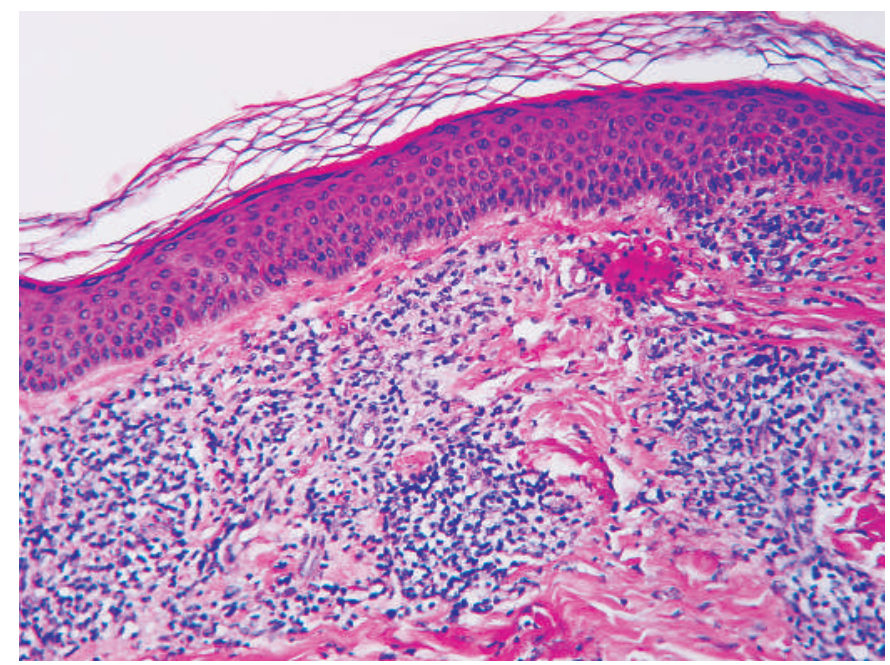

Abb. 4 Granulomatöse Dermatitis - Detailaufnahme.

\section{Diskussion}

Wir berichten über einen weiteren seltenen Fall einer granulomatösen Dermatitis nach einem Herpes Zoster mit dem Nachweis spezifischer Varizella Zoster-Virus-DNA. Entgegen der Ansicht Serflings [14], Varizella-Zoster-Virus spezifische DNA sei nur bis zu einem Monat nach Auftreten der Effloreszenzen möglich, wurde in diesem Fall Virus spezifische DNA drei Monate später noch nachgewiesen. [3,14].

Interessant ist auch der Zusammenhang mit der Hepatitis C-Virus-Infektion. Unbestritten gilt die Hepatitis C-Virus-Infektion als Trigger für das Auftreten eines Lichen ruber planus [8]. Aber auch eine postzosterische granulomatöse Dermatitis kann eine hepatobiliäre Erkrankung wiederspiegeln [9]. Die direkte Verknüpfung über eine immunologische Fehlregulation erscheint hier möglich, zumal eine aktive, chronische Hepatitis $C$ mit verschiedenen immunologischen Erkrankungen verknüpft ist [10]. Der Trigger für den immunologischen Prozess, der zu Hautmanifestationen führen kann, sind aktivierte T-Zellen ( CD8 und zytotoxische T-Lymphozyten) und Zytokine [12].
Nicht nur das Hepatitis C-Virus, sondern auch das Varizella-Zoster-Virus kann eine atypische verzögerte Hypersensitivitätsreaktion auslösen. In der Literatur wird mehrfach verneint, dass eine Assoziation zwischen Varizella-Zoster-Virus-DNA und dem Auftreten granulomatöser Formationen besteht [14]. Nikkels et al. fanden jedoch kleinste, in den Zosternarben persistierende Virusproteine [11]. Diese, so Nikkels, seien für die verzögerte Hypersensitivitätsreaktion und somit für das Auftreten einer granulomatösen Dermatitis verantwortlich [3]. Hierbei handelt es sich um die Glykoproteine gpI und gpII, die in den Granulomen nachgewiesen wurden.

In beiden Fällen, sowohl bei persistierender HCV RNA als auch bei persistierender VZV DNA, ist histopathologisch kein typischer Zellschaden allein durch Virus-DNA oder -RNA nachweisbar $[4,8]$. Das Zusammenspiel beider Immunphänomene ist bisher unbekannt.

Solange die Pathogenese unklar bleibt, ist es auch schwierig, eindeutige Therapieempfehlungen zu geben. Kortikosteroide wurden mit unterschiedlichem Erfolg eingesetzt [2,4]. Aber auch die antivirale Therapie ist umstritten, zumal häufig virusspezifische DNA nicht nachweisbar ist und diese auch nicht für das Auftreten der granulomatösen Veränderungen verantwortlich gemacht wird [4,5]. Eine selbständige Regeneration ohne Therapie wird in der Literatur aber ebenfalls berichtet [4].

\section{Literatur}

${ }^{1}$ Bygum A. Granuloma annulare after herpes zoster: isotopic response. Ugeskr Laeger 1998; 160: 4429-4430

${ }^{2}$ Cordoba $\mathrm{S}$ et al. Giant cell lichenoid dermatitis within herpes zoster scars in a bone marrow recipient. J Cutan Pathol 2000; 27: 255-257

${ }^{3}$ Gesierich A, Krahl D et al. Granulomatous dermatitis following herpes zoster with detection of varicella zoster virus DANN. JDDG 2004; 2: $770-772$

${ }^{4}$ Gibney MD et al. Cutaneous reactions following herpes zoster infections: report of three cases and a review of the literature. Br J Dermatol 1996; 134: $504-509$

${ }^{5}$ Gutzmer R et al. Post-zoster granuloma with detection of varicella zoster virus DANN in the granulomas. Hautarzt 2001; 52: 1111 - 1114

${ }^{6}$ Ignatova TM et al. Extrahepatic manifestations of chronic hepatitis C. Ter Arkh 1998; 70: 9-16

${ }^{7}$ LaGuardia JJ et al. Prevalence of varicella-zoster virus DANN in dissociated human trigeminal ganglion neurons and nonneuronal cells. J Virol 1999; 73: 8571-8577

${ }^{8}$ Mangia A et al. Lack of hepatitis $C$ virus replication intermediate RNA in deseased skin tissue of chronic hepatitis C patientes. J Med Viro 1999; 59: $277-280$

${ }^{9}$ Margo CM et al. Lichenoid and granulomatous dermatitis. Int J Dermatol 2000; 39: 126-133

${ }^{10}$ Malaguarnera $\mathrm{M}$ et al. Immunologic diseases and hepatitis $\mathrm{C}$ virus. Rev Med Interne 1996; 17: 305-312

${ }^{11}$ Nikkels AF et al. Viral glycoproteins in herpesviridae granulomas. Am J Dermatopathol 1994; 16: $588-592$

12 Podanyi B et al. Skin deseases associated with chronic hepatitis C. Orv Hetil 1998; 139: 2633 - 2637

${ }^{13}$ Requena L et al. Cutaeous reactions at sites of herpes zoster scars: an expanded spectrum. Br J Dermatol 1998; 138: 161 - 168

${ }^{14}$ Serfling U et al. Varicella-zoster virus DANN in granulomatous skin lesions following herpes zoster. A study by the polymerase chain reaction. J Cutan Pathol 1993; 20: 28-33 